\title{
Brazilian Journal of Chemical

\section{CFD AND EXPERIMENTAL INVESTIGATION ON THE HEAT TRANSFER CHARACTERISTICS OF ALUMINA NANOFLUIDS UNDER THE LAMINAR FLOW REGIME}

\author{
A. Azari ${ }^{1}$, M. Kalbasi ${ }^{1 *}$ and M. Rahimi ${ }^{2}$ \\ ${ }^{1}$ Department of Petrochemical Engineering, Amirkabir University of Technology (Tehran Polytechnic), \\ Mahshahr Campus, Mahshahr, P.O. Box 415, Iran. \\ Phone/Fax: + 98-65223-43645. \\ E-mail: mkalbasi2000@yahoo.com; mkalbasi@aut.ac.ir \\ ${ }^{2}$ CFD Research Center, Chemical Engineering Department, Razi University, TagheBostan, Kermanshah, Iran.
}

(Submitted: May 22, 2012 ; Revised: November 3, 2012 ; Accepted: June 24, 2013)

\begin{abstract}
This study reports experimental and Computational Fluid Dynamics (CFD) investigations of the laminar convective heat transfer coefficient of $\mathrm{Al}_{2} \mathrm{O}_{3}$ /water nanofluids in a circular tube under uniform and constant heat flux on the wall. Three different models including a constant physical properties single-phase (CP-SP) model, a variable physical properties single-phase (VP-SP) model and a discrete particles two-phase model were developed. Particle agglomeration and cluster size distribution were considered in the two-phase model. Experimental and simulation results showed that the thermal performance of nanofluids is higher than that of the base fluid and the heat transfer enhancement increases with the particle volume concentration and Reynolds number. Furthermore, higher heat transfer coefficients were detected in the case of the VP-SP model and the two-phase model. The results demonstrated that the two-phase model prediction and experimental data match significantly and that the model can be employed with confidence for the prediction of any type of nanofluid.

Keywords: Nanofluids; Heat transfer coefficient; Single-phase model; Two-phase model.
\end{abstract}

\section{INTRODUCTION}

Convective heat transfer is very important for many industrial heating or cooling equipments. The heat convection can be enhanced passively by changing the flow geometry or the boundary conditions or by enhancing the fluid thermophysical properties. An innovative way of improving the thermal conductivities of fluids is to suspend small solid particles in the fluid. Maxwell $(1873,1881)$ showed the possibility of increasing thermal conductivity of a mixture by adding a volume fraction of solid particles. These fluids containing suspended colloidal nanoparticles have been called nanofluids.
Theoretical and experimental investigations have been conducted to estimate the effective thermal conductivity of nanofluids. Some experimental studies (Yoo et al., 2007; Choi et al., 2001) show that the measured thermal conductivity of nanofluids is much larger than the classical theoretical predictions (Hamilton and Crosser, 1962). Other experimental investigations (Putman et al., 2006; Zhang et al., 2007) revealed that the thermal conductivity did not show any anomalous enhancement and, for lower volume fractions, the results agree well with the classical equations (Yamada and Ota, 1980; Hamilton and Crosser, 1962). Many attempts have been made to formulate efficient theoretical models for the

*To whom correspondence should be addressed 
prediction of the effective thermal conductivity, but this topic is still seriously incomplete (Chon et al., 2005; Xue, 2003; Xuan et al. 2004; Li et al., 2003).

Several investigations revealed that the nanofluid heat transfer coefficient could also be increased by more than $20 \%$ in the case of very low nanoparticles concentrations (Kang et al., 2006; Xuan and Li, 2000). Relatively, few theoretical and experimental investigations have been reported on convective heat transfer in confined flows, as also reviewed in the literature (Buongiorno, 2006; Das et al., 2006; Daungthongsuk and Wongwises, 2007; Wang and Mujumdar, 2007). However, only limited experimental studies on the convective heat transfer of nanofluids as modified heat transfer media have been performed, compared with many results for thermal conductivity enhancement (Chen et al., 2008; Ding et al., 2006; He et al., 2007; Pak and Cho, 1998; Wen and Ding, 2004; Li et al., 2003; Yang et al., 2005).

Numerical investigations on nanofluids are carried out using two approaches. The first approach assumes that the continuum assumption is still valid for fluids with suspended nanosize particles (Moraveji et al., 2011), while the other approach considers a two-phase model for describing both the fluid and the solid phases (Kalteh et al., 2011). Another approach is to adopt the Boltzmann theory.

The single-phase model with physical and thermal properties, all assumed to be constant with temperature, was employed in several studies (Roy et al., 2004; Maiga et al., 2004; Maiga et al., 2006; Maiga et al., 2005). The hydrodynamic and thermal characteristics of nanofluids, flowing through a uniformly heated tube, in both laminar and turbulent regimes with adjusted properties, have been investigated (Maiga et al., 2004). The advantages of nanofluids with respect to heat transfer were discussed (Maiga et al., 2005), but it was also found that the inclusion of nanoparticles introduced drastic effects on the wall shear stress. A new correlation was proposed (Maiga et al., 2006) to describe the thermal performance of $\mathrm{Al}_{2} \mathrm{O}_{3} /$ water nanofluids under the turbulent regime and a numerical study of heat transfer for water $/ \mathrm{Al}_{2} \mathrm{O}_{3}$ nanofluids in a radial cooling system was carried out by Roy et al. (2004). They found that the addition of nanoparticles in the base fluid increased the heat transfer rates considerably.

Recently, numerous other theoretical investigations by different researchers (Bianco et al., 2009; Ebrahimnia-Bajestan et al., 2011; Farsad et al., 2011; Fazeli et al., 2012; Haghshenas Fard et al.,
2010; Kalteh et al., 2012; Kamali and Binesh, 2010; Kamyar et al., 2012; Mahmoodi and Hashemi, 2012; Manca et al., 2012; Rana and Bhargava, 2011; Rostamani et al., 2010; Singh et al., 2012; Tahery et al., 2011; Yang and Lai, 2011; Yu et al., 2011) on nanofluid convective heat transfer were carried out, but all of them did not consider the van der Walls interaction and agglomeration phenomena of the nanoparticles.

This study aims to investigate the effect of particle agglomeration and cluster size distribution on the convective heat transfer performance of $\mathrm{Al}_{2} \mathrm{O}_{3}$ /water nanofluids. Moreover, experiments were performed using $\mathrm{Al}_{2} \mathrm{O}_{3}$ nanofluids inside a straight circular tube under uniform heat flux and in the laminar flow regime. The cluster size distribution due to particle agglomeration was analyzed and used for the numerical modeling. The single-phase and the two-phase models for the prediction of nanofluid heat transfer coefficients were developed. The singlephase model with constant and variable physical properties and also the discrete particle two-phase model with particle agglomeration and clustering were considered. A commercial CFD code (Fluent, 2006) was employed to solve the governing equations. The numerical simulation results were also compared with the experimental data and some interesting results were obtained.

\section{MATERIALS AND METHODS}

\section{Materials and Nanofluid Preparation}

In order to investigate the effects of nanoparticles on heat transfer, alumina nanofluids were prepared without any surfactant using deionized water as the base fluid and the two-step method with a stirrer and a sonicator. Before conducting the main heat transfer experiments, stability analysis of 0.5 vol.\% alumina nanofluids at different $\mathrm{pH}$ were performed to investigate the period of the nanoparticles stability in the fluid. Figure 1 show the stability results after 26 days. The results clearly show that the stability period for the same concentration of alumina nanofluids varies with the $\mathrm{pH}$ value and the period of stability at low $\mathrm{pH}$ is greater than at high $\mathrm{pH}$. Thus, in all the nanofluid experiments $\mathrm{pH}$ value was controlled at about 3. Nanoparticles were supplied by PlasmaChem ${ }^{\circledR}$ Company (Berlin, Germany). The physical properties of the alumina are reported in Table 1 and the Xray diffraction (XRD) image is shown in Figure 2. 


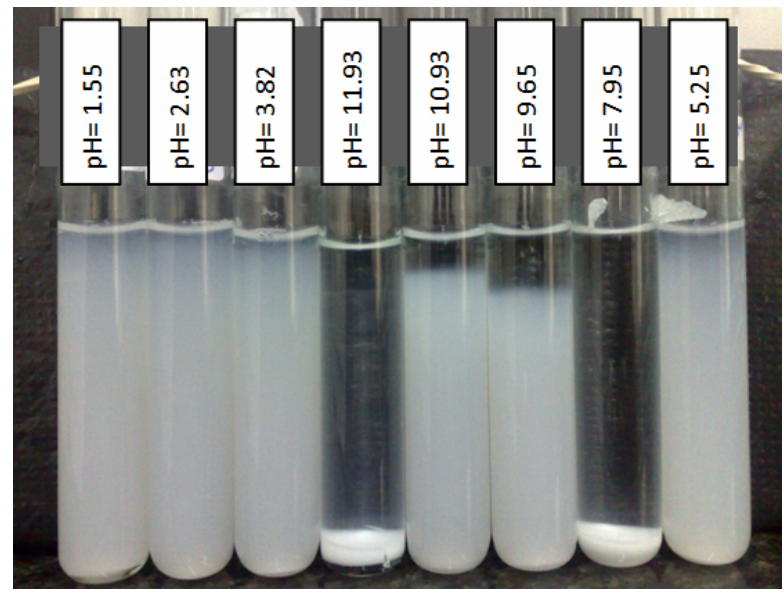

Figure 1: Stability analysis of 0.5 vol. $\%$ alumina nanofluids at different $\mathrm{pH}$ after 26 days.

Table 1: Physical properties of $\mathrm{Al}_{2} \mathrm{O}_{3}$ nanoparticles.

\begin{tabular}{|c|c|c|c|c|c|c|c|}
\hline $\begin{array}{c}\text { X-Ray } \\
\text { Analysis }\end{array}$ & $\begin{array}{c}\text { Particle } \\
\text { Shape }\end{array}$ & $\begin{array}{c}\text { Average } \\
\text { diameter } \\
(\mathbf{n m})\end{array}$ & $\begin{array}{c}\text { Density } \\
\left(\mathbf{k g} / \mathbf{m}^{\mathbf{3}}\right)\end{array}$ & $\begin{array}{c}\text { Thermal } \\
\text { Conductivity } \\
(\mathbf{W} / \mathbf{m} . \mathbf{K})\end{array}$ & $\begin{array}{c}\text { Specific heat } \\
(\mathbf{J} / \mathbf{k g} . \mathbf{K})\end{array}$ & $\begin{array}{c}\text { Specific surface } \\
\left(\mathbf{m}^{\mathbf{2}} / \mathbf{g r}\right)\end{array}$ & Purity \\
\hline$\gamma-\mathrm{Al}_{2} \mathrm{O}_{3}$ & Spherical & 40 & 3920 & 40 & 880 & $>40$ & $>99.9 \%$ \\
\hline
\end{tabular}

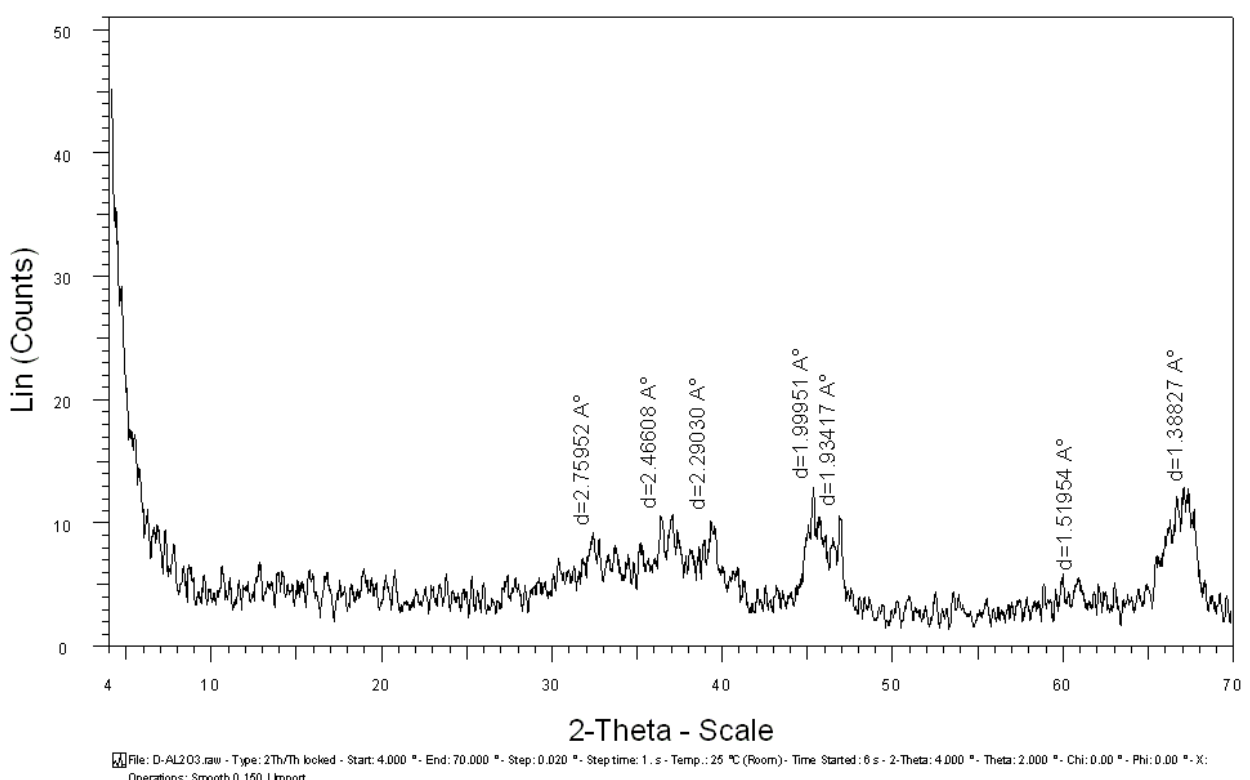

Figure 2: XRD image of $\mathrm{Al}_{2} \mathrm{O}_{3}$ nanoparticles.

\section{Experimental Setup}

The experimental system for measuring the local convective heat transfer coefficient is shown in Figure 3. The test loop included a heat transfer section, a nanofluid reservoir tank, a water reservoir tank, two pumps for nanofluid and cooling water, and two needle valves for controlling the flow rate, a plate heat exchanger and a pressure drop measuring unit. The heat transfer test section was constructed of a copper tube with an inner diameter of $7.8 \mathrm{~mm}$, a $2 \mathrm{~mm}$ thickness and $0.873 \mathrm{~m}$ length. Six K-type thermocouples with the precision of $0.1{ }^{\circ} \mathrm{C}$ were soldered at different axial distances on the test 


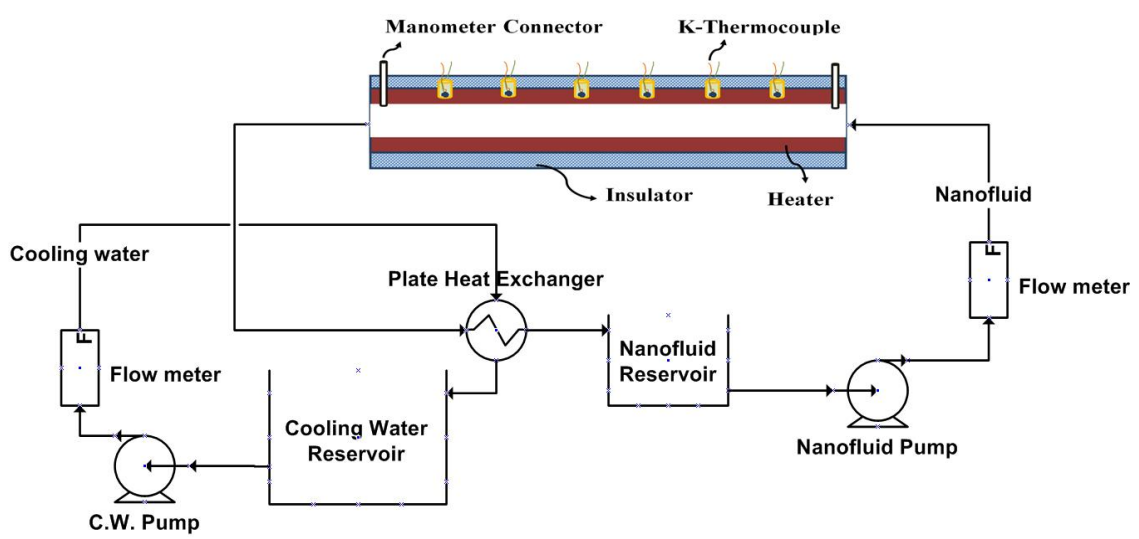

Figure 3: Experimental system for the measurement of the local convective heat transfer coefficient.

section to measure the wall temperature, and two Ttype thermocouples with the precision of $0.1{ }^{\circ} \mathrm{C}$ were inserted to measure the bulk temperature at the inlet and outlet of the test section. In order to minimize heat radiation to the surroundings, a thick thermal isolating layer surrounded the test section. To obtain a constant heat flux condition, the heat transfer section was heated electrically by a constant power supply. The plate heat exchanger was used to maintain the inlet temperature of the test fluids at about $25 \pm 1{ }^{\circ} \mathrm{C}$ for all tests. The flow rate was controlled by adjusting the needle valve attached to the inlet of the test section. The volume flow rate of the test fluids was measured by a flow meter with the precision of $0.01 \mathrm{~L} / \mathrm{min}$. All data were recorded with a data acquisition system during the experimental runs.

\section{Data Processing}

Thermophysical properties of the nanofluids such as density, viscosity and thermal conductivity are the fundumental and significant parameters for evaluating the heat transfer performance. Nanofluid properties are normally expressed in nanoparticle volume fraction $\phi$. The density $(\rho)$ of the nanofluids is defined by:

$\rho_{n f}=\phi \rho_{p}+(1-\phi) \rho_{f}$

where the subscripts " $n f$ ", " $p$ " and " $f$ " stand for nanofluid, particle and fluid properties, respectively. Assuming thermal equilibrium between the particles and the surrounding fluid, the specific heat is estimated as follows:

$C p_{n f}=\frac{\phi \rho_{p} C p_{p}+(1-\phi) \rho_{f} C p_{f}}{\rho_{n f}}$
The effective viscosity of nanofluids at different volume fractions was experimentally measured and the results are shown in Figure 4. The Einstein equation for compression is also plotted in Figure 4.

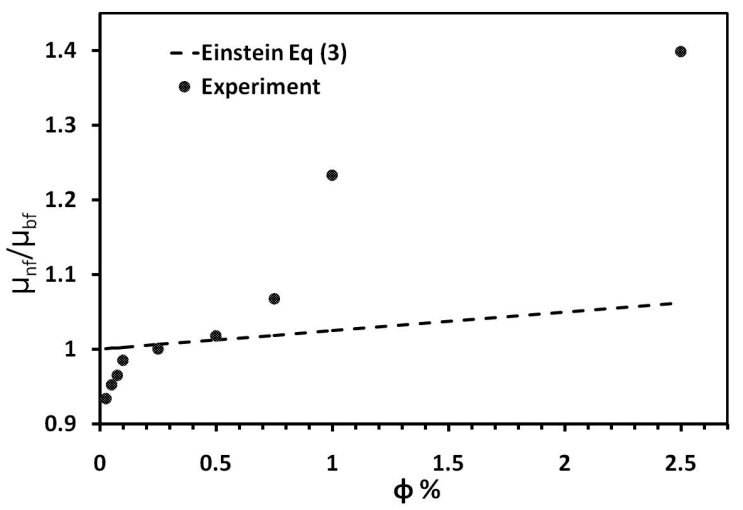

Figure 4: Experimental effective viscosity ratio of water-based alumina nanofluids.

As shown in the figure, at low volume fractions $(\phi<0.15 \%)$ the viscosity ratio is smaller than the Einstein equation prediction. This may be due to the decrease in the water intermolecular force by using nanoparticles at very low volume fractions. For highvolume-fraction nanofluids, the Einstein equation underestimates the alumina nanofluid viscosity.

$$
\frac{\mu_{n f}}{\mu_{f}}=1+2.5 \phi
$$

Equation (3) applies to suspensions of low particle concentration (usually $<1$ vol.\%), where particleparticle interactions are negligible. Curve fits used in this study for the viscosity of alumina/water nanofluids based on the experimental data in Figure 4 are given by Equation (4). 
$\mu_{n f}(\phi, T)=\mu_{f}(T)(0.951+0.188 \phi)$

The experimental thermal conductivity data for an alumina nanofluid were initially reported by Williams et al. (2008) as Equation (5).

$k_{n f}(\phi, T)=k_{f}(T)(1+4.5503 \phi)$

The applicable temperature range of this equation is $20{ }^{\circ} \mathrm{C}<\mathrm{T}<80{ }^{\circ} \mathrm{C}$, with volumetric loadings up to $6 \%$ for alumina. For the temperature-variable physical property single-phase model, the thermophysical properties of the base fluid, with $T$ expressed in $K$, are (Bianco et al., 2009):

$$
\begin{aligned}
k_{f}(T) & =-1.13+9.71 \times 10^{-3} T-1.31 \times 10^{-5} T^{2} \\
\mu_{f}(T) & =7.57 \times 10^{-2}-6.37 \times 10^{-4} T \\
& +1.8 \times 10^{-6} T^{2}-1.73 \times 10^{-9} T^{3}
\end{aligned}
$$

The local convective heat transfer coefficient was derived from Newton's law of cooling, Equation (8).

$h(x)=\frac{q^{\prime \prime}}{T_{w}(x)-T_{b}(x)}$

where $q^{\prime \prime}$ is the heat flux, $x$ is the axial distance from the inlet of the heat transfer test section, and $T_{w}$ and $T_{b}$ are the wall and fluid average bulk temperatures, respectively. The representative dimensionless coefficient of heat transfer, the Nusselt number, is defined as:

$$
N u(x)=\frac{h(x) \cdot D}{k}
$$

where $D$ is the diameter of the inner tube and $k$ is the thermal conductivity of the fluid. The wall and fluid temperatures and the heat flux were measured to calculate the convective heat transfer coefficient. For constant surface heat flux, the fluid mean temperature was calculated as follows:

$T_{b}(x)=T_{b, i n}+\frac{q^{\prime \prime} \cdot P}{\dot{m} \cdot C_{p}} x$

where $P$ is the surface perimeter ( $P=\pi D$ for a circular tube), $\dot{m}$ is the mass flow rate, and $C_{p}$ is the specific heat.

The uncertainty in the experimental results may arise from the measuring errors of parameters such as temperature and flow rate. A detailed systematic error analysis was performed by Beckwith et al. (1990) to estimate the errors associated with the experimentation. The uncertainty table for different instruments used in the experiment is given in Table 2. The maximum possible errors for the parameters involved in the analysis were estimated and summarized in Table 3.

Table 2: Uncertainties of instruments and properties.

\begin{tabular}{|l|c|l|c|c|c|}
\hline $\begin{array}{l}\text { Name of } \\
\text { instrument }\end{array}$ & $\begin{array}{c}\text { Range of } \\
\text { instrument }\end{array}$ & \multicolumn{1}{|c|}{$\begin{array}{c}\text { Variable } \\
\text { measured }\end{array}$} & $\begin{array}{c}\text { Least division in } \\
\text { measuring instrument }\end{array}$ & $\begin{array}{c}\text { Min. and Max. values } \\
\text { measured in experiment }\end{array}$ & $\begin{array}{c}\text { \% Uncertainty } \\
\text { (U) }\end{array}$ \\
\hline $\begin{array}{l}\text { Thermocouple } \\
\text { Thermocouple }\end{array}$ & $0-120^{\circ} \mathrm{C}$ & Wall temperature, $\mathrm{T}_{\mathrm{w}}$ & $0.1{ }^{\circ} \mathrm{C}$ & $23-66^{\circ} \mathrm{C}$ & 0.56 \\
Flow controller & $0-120^{\circ} \mathrm{C}$ & bulk temperature, $\mathrm{T}_{\mathrm{b}}$ & $0.1{ }^{\circ} \mathrm{C}$ & $24-40^{\circ} \mathrm{C}$ & 0.88 \\
$\begin{array}{l}\mathrm{U}-\text { tube } \\
\text { manometer }\end{array}$ & $0-1000 \mathrm{~mm}$ & $\begin{array}{l}\text { Mass flow rate, } m \\
\text { Height of the nanofluid }\end{array}$ & $0.01 \mathrm{~L} / \mathrm{min}$ & $0.3-2.2 \mathrm{~L} / \mathrm{min}$ & $0.45-3.30$ \\
& & $1 \mathrm{~mm}$ & $10-650 \mathrm{~mm}$ & $0.15-10.00$ \\
\hline
\end{tabular}

Table 3: Uncertainty of parameters and variables.

\begin{tabular}{|l|c|}
\hline Variable name & \% Uncertainty error \\
\hline Reynolds number, Re & 0.32 \\
Heat flux, $\mathrm{q}$ & 3.3 \\
Heat transfer coefficient, $\mathrm{W} / \mathrm{m}^{2} \mathrm{~K}$ & 4.8 \\
Friction factor & 1.6 \\
Nusselt number & 5.0 \\
Pressure drop & 5.0 \\
$\mathrm{~h}_{\mathrm{nf}} / \mathrm{h}_{\mathrm{bf}}$ & 6.8 \\
\hline
\end{tabular}




\section{MATHEMATICAL MODELING}

Figure 5 shows the geometrical configuration used in this study. The fluid enters with uniform temperature and velocity at the inlet section. The condition of axially and circumferentially uniform wall heat flux was considered in this study. The single-phase and two-phase models were also implemented to compare their predictions with the experimental data.

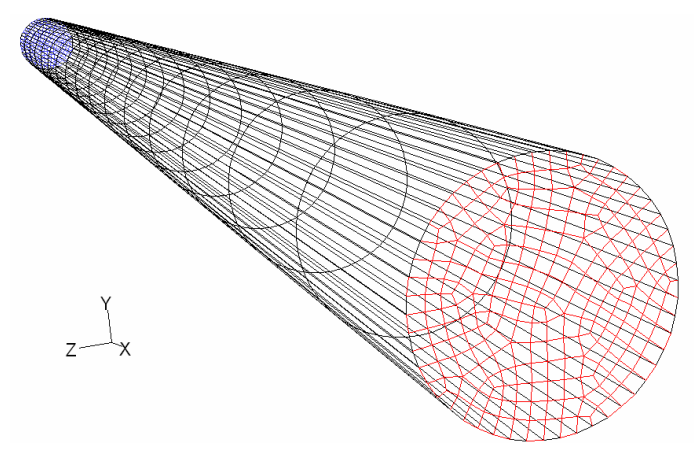

Figure 5: Geometrical configuration used in this study.

\section{Governing Equations for the Single-Phase and Two- Phase Models}

Governing equations for the continuous phase include the continuous equation, equation of motion and energy equation. They are given, respectively, by the following (He et al., 2009).

Continuous equation:

$\frac{\partial \rho_{f}}{\partial t}+\nabla \cdot\left(\rho_{f} v_{f}\right)=0$

Momentum equation:

$$
\frac{\partial \rho_{f} v_{f}}{\partial t}+\nabla \cdot\left(\rho_{f} v_{f} v_{f}\right)=-\nabla p+\nabla \cdot T_{f}-S_{p}+\rho_{f} g
$$

Energy equation:

$\rho_{f} C p_{f}\left[\frac{\partial T}{\partial t}+v_{f} \cdot \nabla T\right]=\nabla \cdot(k \nabla T)$

$T_{f}$ in Equation (12), stress tensor is defined as:

$T_{f}=\mu_{f}\left[\nabla v_{f}+\nabla v_{f}^{T}\right]-\frac{2}{3} \mu_{f} \nabla \cdot v_{f} I$

where $\mu_{f}$ is the fluid-phase shear viscosity and $\mathrm{I}$ is the unit vector. $S_{p}$ in Equation (12) is the source term representing the momentum transfer between the fluid and particle phases and its value is zero for the single-phase model. The $S_{p}$ value for the twophase model is obtained by computing the momentum variation of particles as they pass through the control volume for the fluid phase, given by:

$S_{p}=\sum F m_{p} \Delta t$

where $\mathrm{F}$ is the total force acting on a particle and $\mathrm{m}_{\mathrm{p}}$ is the mass of the particle. The equation of motion of a nanoparticle, in the Lagrangian frame of reference, is given by:

$\frac{d v_{p}}{d t}=F$

where $v_{p}$ is the particle velocity. $\mathrm{F}$ is given in the following which includes contributions from the drag force, gravity, Brownian force, thermophoresis force, Saffman's lift force, pressure gradient and virtual mass force, and its complete detailed description is presented in He et al. (2009).

$$
F=F_{D}+F_{G}+F_{B}+F_{T}+F_{L}+F_{P}+F_{V}
$$

\section{Particle Agglomeration with Rosin-Rammler Diameter Distribution}

In order to consider the particle agglomeration in the nanofluid during the time of the experiments, the particle size distribution was measured using the dynamic light scattering (DLS) method and the size distribution data were fitted to the Rosin-Rammler equation. The Rosin-Rammler distribution function is based on the assumption that an exponential relationship exists between the particle diameter, $d$, and the mass fraction of particles with diameters greater than d, $Y_{d}$ (Fluent, 2006):

$Y_{d}=e^{-(d / \bar{d})^{n}}$

In this study, by fitting the DLS data with Equation (18), the value of $\bar{d}$ and $n$ obtained were equal to $0.996008 \mu \mathrm{m}$ and 1.175 , respectively.

\section{Boundary Conditions}

At the tube inlet, a uniform axial velocity $\mathrm{V}_{0}$ and temperature $T_{0}$ prevail and the two-phases have the 
same temperature and velocity at the inlet. Moreover, in the case of temperature-dependent properties, the reference viscosity value for Re calculation was taken at $T_{0}$. At the tube exit section, the fully developed conditions prevail, that is to say, all axial derivatives are zero. No-slip conditions for the fluid phase, the reflection condition for the solid phase and uniform heat flux were imposed on the tube wall.

\section{Numerical Method}

The computational fluid dynamics code Fluent was used for solving this problem. The system of governing Equations (11)-(14) was solved by the control-volume approach. The control-volume technique converts the governing equations to a set of algebraic equations that can be solved numerically. The control-volume approach employs the conservation statement or physical law represented by the entire governing equations over finite control volumes. A second order upwind scheme was employed to discretize the convection terms, diffusion terms and other quantities resulting from the governing equations. Pressure and velocity were coupled using the Semi Implicit Method for Pressure Linked Equations (SIMPLE). Fluent solves the linear systems resulting from discretization schemes using a point implicit (Gauss-Seidel) linear equation solver in conjunction with an algebraic multigrid method. During the iterative process, the residuals were carefully monitored. For all simulations performed in the present study, solutions were considered to have converged when the residuals resulting from the iterative process for all governing Equations (11)(14) were lower than $10^{-7}$.

In order to determine the grid independency of the simulated results, different combination of nodes in the radial, tangential and axial directions were investigated. The simulated results for outlet velocity and temperature of the nanofluid are listed in Table 4. The grid selected for the present calculations was 20, 400 and 30 nodes for the r-direction, x-direction and tangential-direction, respectively. The results of Table 4 (b) show that all of structures gave similar values for the velocity and temperature at the outlet. Therefore, the mentioned nodes were accepted as the optimal ones.

\section{RESULTS AND DISCUSSIONS}

In this section, for simplicity, the single-phase model with constant physical properties, or CP-SP model, and the single-phase model with variable physical properties, the VP-SP model, are discussed. Meanwhile, the discrete-phase modeling of nanoparticles with agglomeration in the base fluid is discussed as the two-phase model.

Table 4 (a): Alumina nanofluid characteristics used for the grid independency investigation.

\begin{tabular}{|l|c|}
\hline Variable & Value \\
\hline Inlet temperature $(\mathrm{K})$ & 298.15 \\
Reynold number & 1301.5 \\
Heat flux $\left(\mathrm{W} / \mathrm{m}^{2}\right)$ & 91313.5 \\
Tube length $(\mathrm{mm})$ & 873 \\
Flow rate $\left(\mathrm{cm}^{3} / \mathrm{s}\right)$ & 0.505 \\
Velocity $(\mathrm{m} / \mathrm{s})$ & 0.304 \\
Tube diameter (mm) & 7.8 \\
Nanoparticle concentration (vol.\%) & 2.5 \\
\hline
\end{tabular}

Table 4 (b): Grid independency results for the selected control volume.

\begin{tabular}{|c|c|c|}
\hline $\begin{array}{c}\text { Grids number } \\
\text { (radial, axial, } \\
\text { tangential) }\end{array}$ & $\begin{array}{c}\text { Nanofluid outlet } \\
\text { temperature } \\
\text { (K) }\end{array}$ & $\begin{array}{c}\text { Nanofluid outlet } \\
\text { velocity } \\
\text { (m/s) }\end{array}$ \\
\hline$(20.400,30)$ & 309.2379 & 0.3042 \\
$(40.600,60)$ & 309.2314 & 0.3046 \\
$(40.400,60)$ & 309.2351 & 0.3044 \\
$(40.600,30)$ & 309.2330 & 0.3045 \\
$(20.600,30)$ & 309.2324 & 0.3046 \\
$(40.400,30)$ & 309.2362 & 0.3043 \\
$(20.400,60)$ & 309.2357 & 0.3042 \\
$(20.600,60)$ & 309.2322 & 0.3045 \\
\hline
\end{tabular}

\section{Validation of the Experimental Setup and Model}

Before performing organized experiments on nanofluids, the reliability and accuracy of the experimental set-up should be examined. Hence, deionized water was used to test the experimental system with constant heat flux as the boundary condition. The results were compared with the predictions of the following well-known Shah equation for laminar flows under the constant heat flux boundary condition (Shah, 1975).

$$
N u=\left\{\begin{array}{ll}
1.953\left(\operatorname{Re} \operatorname{Pr} \frac{D}{x}\right)^{1 / 3} & \left(\operatorname{Re} \operatorname{Pr} \frac{D}{x}\right) \geq 33.3 \\
4.364+0.0722 \operatorname{Re} \operatorname{Pr} \frac{D}{x} & \left(\operatorname{Re} \operatorname{Pr} \frac{D}{x}\right)<33.3
\end{array}\right\}
$$

The axial profile of the local heat transfer coefficient is shown in Figure 6 for Reynolds numbers of 1724 and 1137 . Reasonably good agreement can be observed between the Shah equation and the experimental measurements at the two Reynolds numbers used in this study. The average discrepancies are about $4.1 \%$ and $4.8 \%$ for the Reynolds numbers of 1724 
and 1137, respectively. The exact reason for the discrepancy is not clear; a difference in the tube size may be one of the reasons. The Shah equation was developed on the basis of laminar flows in large channels (Celata et al., 2004; Guo and Li, 2003), while a tube with $7.8 \mathrm{~mm}$ inner diameter was used in this study.

In order to demonstrate the validity and also the precision of the model and the numerical procedure, comparisons with the experimental results have been made, as shown in Figure 6. The computer model was successfully validated with the experimental data, showing average relative errors of about 5.3\% and $5.8 \%$ for the Reynolds numbers of 1724 and 1137 , respectively. The validity and precision of the model were tested using water as the fluid.

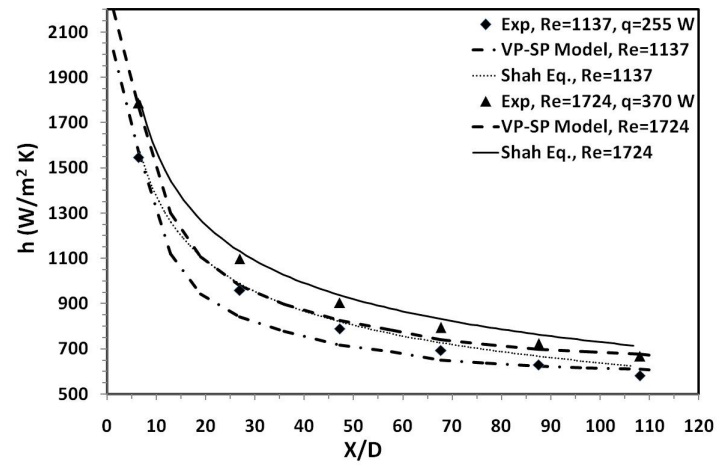

Figure 6: Measured heat transfer coefficient versus dimensionless distance for de-ionized water.

\section{Experimental Results and Aplication of the Model}

Figure 7 represents the experimental results of the local heat transfer coefficient against the dimensionless axial distance from the entrance of the test section at different Reynolds numbers. Due to small variations in viscosity at different particle concentrations, referring to Equation (4), the Reynolds number changes slightly even at a given fluid velocity. The results clearly show that the use of nanofluids significantly improves the convective heat transfer, particularly at the entrance region and at the higher Reynolds number. The local heat transfer coefficient is also seen to increase with particle concentration (volume fraction).

Figure 7 also shows a significant decrease in the heat transfer enhancement with increasing distance from the entrance region. This behaviour indicates that "smart" measures could be taken when using nanofluids for heat transfer enhancement. For example, one may create "artificial entrance" regions along a pipeline to maximize the performance of nanofluids. An inspection of Figure 7 also indicates that the thermal entrance length of the nanofluid flows is longer than that of pure base liquid flows. A comparison of the results in Figure 7 with the result from Equation (5) shows that the enhancement of the local heat transfer coefficient is much more dramatic than the enhancement of the effective thermal conductivity in most parts of the test section. A similar trend was also observed by Li et al. (2003) in the turbulent flow regime. They showed that the local heat transfer coefficient increased by $60 \%$ for a water-based nanofluid containing $2 \% \mathrm{Cu}$ nanopaticles by volume, and the nanofluids had an effective thermal conductivity only approximately $12.5 \%$ higher than that of the base liquid. A number of reasons may be responsible for the enhancement. Particle migration may be a reason for the enhancement, which results in a non-uniform distribution of thermal conductivity and viscosity fields and reduces the thermal boundary layer thickness.

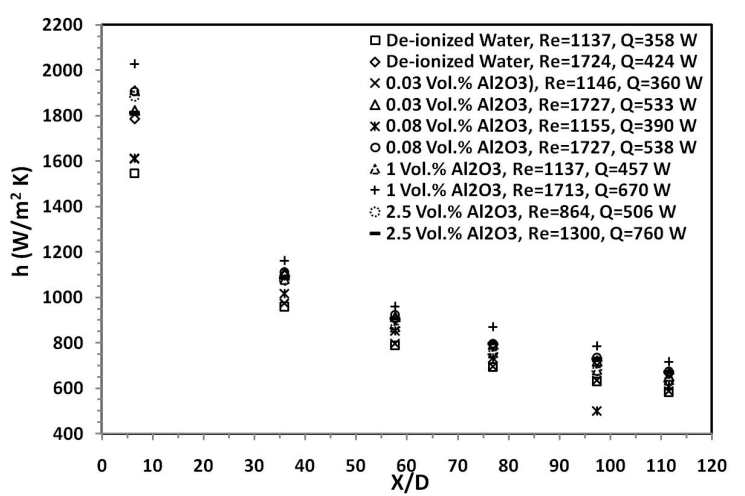

Figure 7: Experimental local heat transfer coefficient of alumina nanofluids at different concentrations and Reynolds numbers.

Figure 8 shows the local heat transfer coefficient at different Reynolds numbers and concentrations compared with different modeling approaches. Figure 8 (a) plots the heat transfer performance of a waterbased nanofluid containing $0.03 \%$ alumina nanoparticles at the Reynolds number equal to 1726 . As shown in the figure, the average relative errors for CP-SP, VP-SP and the two-phase models are 19.9\%, $6.1 \%$ and $8.5 \%$, respectively. Thus, in the case of low nanoparticle concentration, the VP-SP model is the best one. Figure 8 (b) indicates the heat transfer performance of water-based nanofluids containing $1 \%$ alumina nanoparticles at the Reynolds number of 1712; the average relative errors for CP-SP, VP-SP and the two-phase models are $19.2 \%, 5.1 \%$ and $10.7 \%$, respectively. Figures 8 (c)-(d) plots the local heat transfer coefficient for $2.5 \%$ alumina nanofluids at two different Reynolds numbers of 1300 and 864 . 


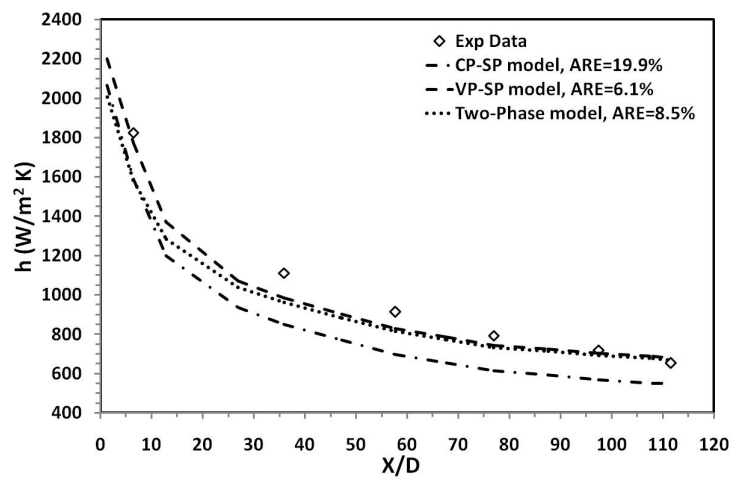

Figure 8 (a): Convective heat transfer coefficient for 0.03 vol. $\% \mathrm{Al}_{2} \mathrm{O}_{3}$ nanofluid at $\mathrm{Re}=1726$ and $\mathrm{Q}=533 \mathrm{~W}$.

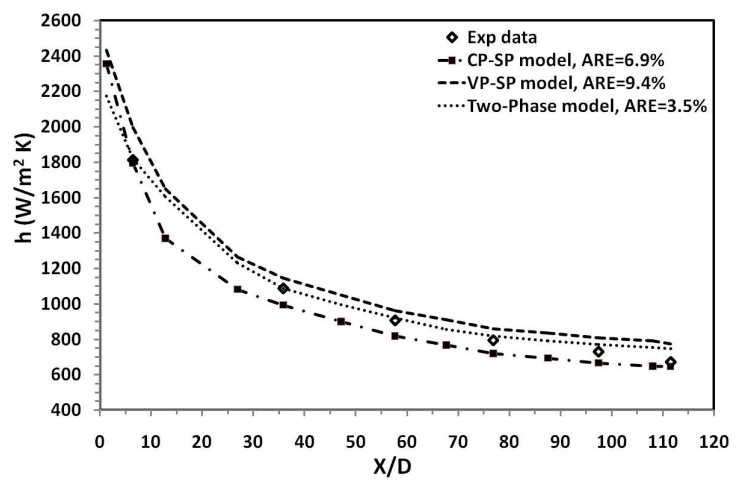

Figure 8 (c): Convective heat transfer coefficient for 2.5 vol. $\% \mathrm{Al}_{2} \mathrm{O}_{3}$ nanofluid at $\mathrm{R}=1300$ and $\mathrm{Q}=761 \mathrm{~W}$.

As shown in these figures, the average relative error at the Reynolds number equal to 1300 for the two-phase model decreases to $3.5 \%$ with respect to the experimental data. This indicates that, by increasing the nanoparticle concentration in the fluid, the two-phase model has better conformity with the experimental data than the VP-SP model. Thus, the results of the VP-SP model are comparable with the two-phase model. At low-particle-volume fractions, the VP-SP model is prefered to the two-phase model and, at high nanoparticle concentrations, the twophase model is prefered to the VP-SP model. The CP-SP model is always weaker than the other two models. Thus, since nanofluids are solid-liquid mixtures, it is better to use the two-phase model at higher nanoparticle concentrations.

Figure 9 compares the two-phase model results with the experimental data for $2.5 \%$ alumina nanofluids. The results show that the two-phase model predicts higher heat transfer coefficients at higher Reynolds numbers.

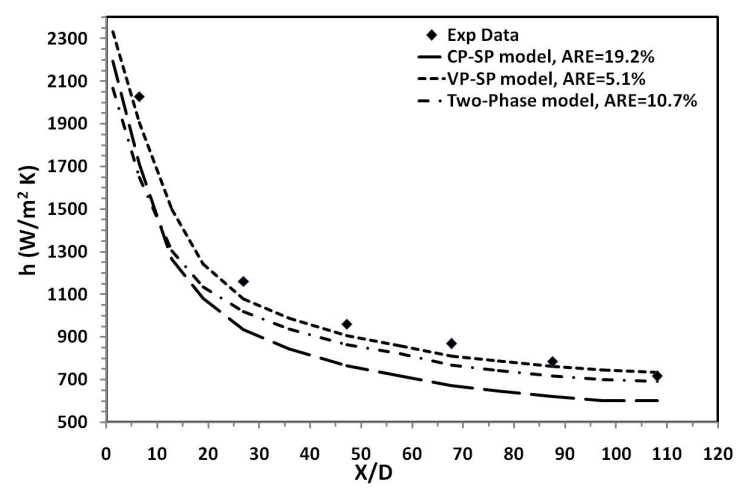

Figure 8 (b): Convective heat transfer coefficient for 1.0 vol. $\% \mathrm{Al}_{2} \mathrm{O}_{3}$ nanofluid at $\mathrm{Re}=1712$ and $\mathrm{Q}=670 \mathrm{~W}$.

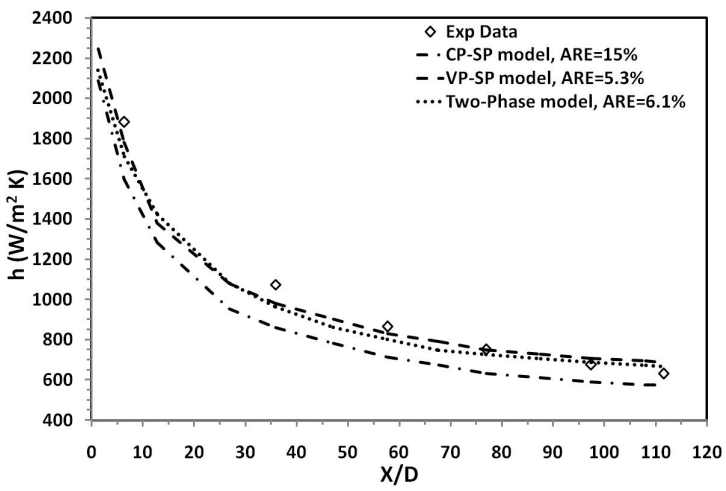

Figure 8 (d): Convective heat transfer coefficient for $2.5 \mathrm{vol} . \% \mathrm{Al}_{2} \mathrm{O}_{3}$ nanofluid at $\mathrm{Re}=864$ and $\mathrm{Q}=505 \mathrm{~W}$.

Figures 10 plots the axial velocity based on the different modeling approaches for $2.5 \%$ alumina nanofluids at the Reynolds number of 1300 and at the positions of $30 \mathrm{~cm}$ and $50 \mathrm{~cm}$ from the entrance of the test section, respectively. Due to the particle migration in the nanofluids, far from the wall of the pipe the velocity magnitude in the two-phase model is smoother than in the latter two models and has a lower velocity gradient in the radial direction.

Figures 11 indicate the axial velocity magnitude profile for $2.5 \%$ alumina nanofluids at different distances from the entrance of the test section at the Reynolds number of 1300 for the two-phase, CP-SP and VP-SP models, respectively. As shown in that figure, the maximum axial velocities at the exit of the test section for the two-phase, CP-SP and VP-SP models are about $0.47,0.59$ and $0.53 \mathrm{~m} / \mathrm{s}$, respectively. Thus, the velocity gradient in the twophase model is lower than in the other models and one important reason may be the particle migration in the base fluid. 


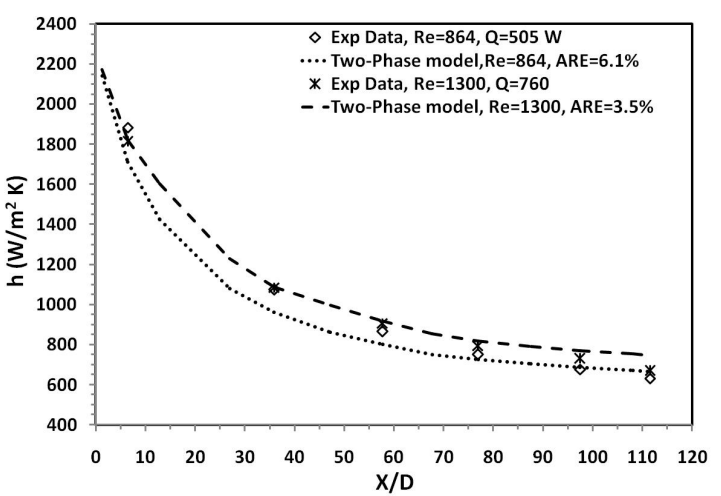

Figure 9: Convective heat transfer coefficient for $2.5 \mathrm{vol} . \% \mathrm{Al}_{2} \mathrm{O}_{3}$ nanofluid at $\mathrm{Re}=864$ and $\mathrm{Re}=1300$.

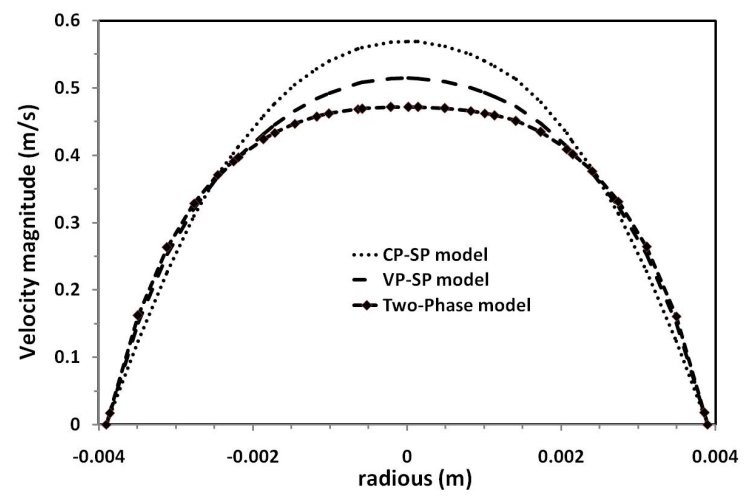

Figure 10 (a): Velocity profile for 2.5 vol. $\% \mathrm{Al}_{2} \mathrm{O}_{3}$ nanofluid at $\mathrm{x}=30 \mathrm{~cm}$ and $\mathrm{Re}=1300$.

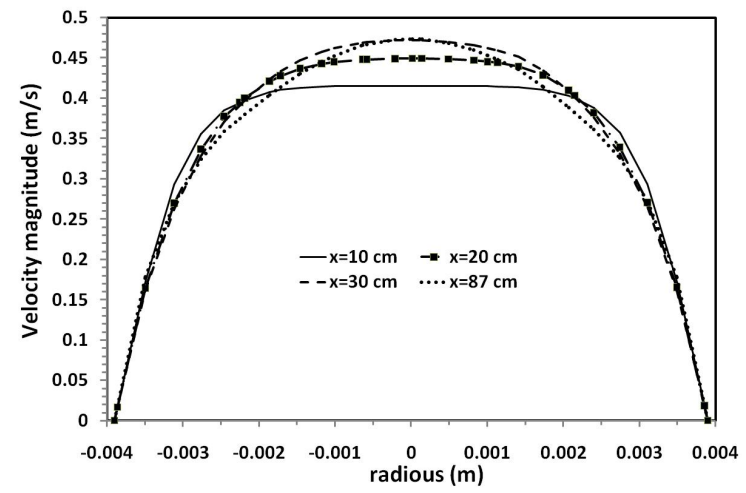

Figure 11 (a): Velocity profile for the two-phase model for 2.5 vol. $\% \mathrm{Al}_{2} \mathrm{O}_{3}$ nanofluid at $\mathrm{Re}=1300$.

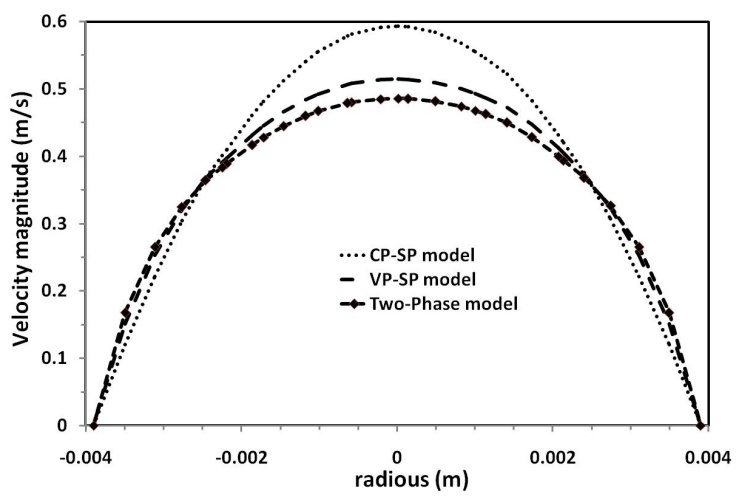

Figure 10 (b): Velocity profile for 2.5 vol. $\% \mathrm{Al}_{2} \mathrm{O}_{3}$ nanofluid at $\mathrm{x}=50 \mathrm{~cm}$ and $\mathrm{Re}=1300$.

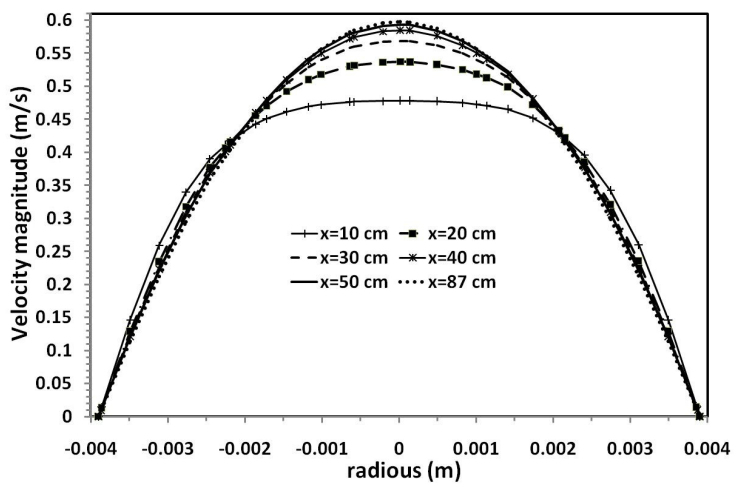

Figure 11 (b): Velocity profile for the CP-SP model for 2.5 vol. $\% \mathrm{Al}_{2} \mathrm{O}_{3}$ nanofluid at $\mathrm{Re}=1300$.

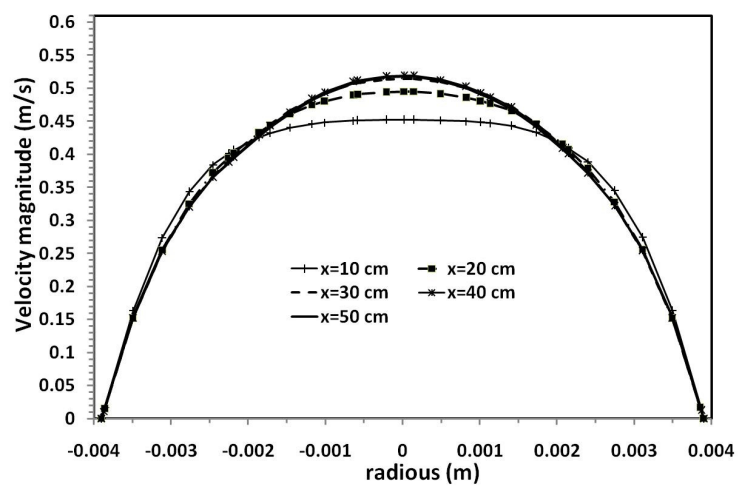

Figure 11 (c): Velocity profile for the VP-SP model for 2.5 vol. $\% \mathrm{Al}_{2} \mathrm{O}_{3}$ nanofluid at $\mathrm{Re}=1300$. 


\section{CONCLUSIONS}

This paper is concerned with the experimental study and modeling of alumina nanofluid convective heat transfer performance in a circular tube under constant heat flux. Simulations were carried out in the laminar flow regime with a constant-property singlephase (CP-SP) model, a variable-property single-phase (VP-SP) model and also a variable-property twophase approach considering nanoparticle aggregation. The following conclusions were obtained:

- The use of $\mathrm{Al}_{2} \mathrm{O}_{3}$ nanoparticles as the dispersed phase in water can significantly enhance the convective heat transfer in the laminar flow regime, and the enhancement increases with Reynolds number, as well as with particle concentration under the conditions of this study.

- The enhancement is particularly significant in the entrance region, and it decreases with axial distance. The thermal developing length of nanofluids is greater than that of the pure base liquid, and increases with an increase in particle concentration.

- The enhancement of the convective heat transfer could not be solely attributed to the enhancement of the effective thermal conductivity. Particle migration may be a reason for the enhancement, which results in a non-uniform distribution of the thermal conductivity and viscosity fields and reduces the thermal boundary layer thickness.

- The VP-SP model is in good agreement with the experimental data when the particle concentration is very low, while at high particle concentrations the twophase model considering particle agglomeration is in good agreement with the experimental results. The CP-SP model always underestimates the experimental results and the results of the two other models.

- Due to particle migration in the two-phase model, the velocity gradient and also the maximum axial velocity are lower than those of the other two models.

\section{NOMENCLATURE}

$\begin{array}{ll}C p & \text { Specific heat of the fluid } \\ D & \text { Tube diameter } \\ F & \text { Total force acting on a } \\ & \text { particle } \\ g & \text { Gravitational acceleration } \\ h & \text { Heat transfer coefficient } \\ I & \text { Unit vector } \\ k & \text { Fluid thermal conductivity } \\ m & \text { Mass } \\ \mathrm{Nu} & \text { Nusselt number } \\ P & \text { Pressure }\end{array}$

$\begin{array}{llr}\operatorname{Pr} & \text { Prandtl number } & \operatorname{Pr}=\mathrm{Cp} \mu_{0} / \mathrm{k} \\ q & \text { Wall heat flux } & \mathrm{W} / \mathrm{m}^{2} \\ \operatorname{Re} & \text { Reynolds number } & \mathrm{Re}=\rho_{0} V_{0} D / \mu_{0} \\ S_{p} & \text { Momentum transfer between } & \\ & \text { the fluid and particle phases } & \mathrm{K} \\ T & \text { Temperature } & \mathrm{sec} \\ t & \text { Time } & \mathrm{m} / \mathrm{s} \\ v & \text { Axial velocity } & \mathrm{m} \\ X & \text { Axial coordinate } & \end{array}$

\section{Greek Symbols}

$\begin{array}{lll}\phi & \begin{array}{l}\text { Particle volume } \\ \text { concentration }\end{array} & \\ \mu & \text { Fluid dynamic viscosity } & \mathrm{kg} / \mathrm{ms} \\ \rho & \text { Fluid density } & \mathrm{kg} / \mathrm{m}^{3}\end{array}$

\section{Subscripts}

$b \quad$ Bulk value

$f \quad$ Fluid

nf Refers to nanofluid property

$p \quad$ Refers to particle property

$w \quad$ Value at tube wall

$0 \quad$ Refers to the reference (inlet) condition

\section{REFERENCES}

Beckwith, T. G., Marangoni, R. D. and Lienhard, J. H., Mechanical Measurements. New York, AddisonWesley Publishing Company, Fifth Ed. (1990).

Bianco, V., Chiacchio, F., Manca, O. and Nardini, S., Numerical investigation of nanofluids forced convection in circular tubes. Applied Thermal Engineering, 29, 3632 (2009).

Buongiorno, J., Convective transport in nanofluids. ASME Journal of Heat Transfer, 128, 240 (2006).

Celata, G. P., Cumo, M. and Zummo, G., Thermalhydraulic characteristics of single-phase flow in capillary pipes. Exp. Thermal Fluids Sci., 28, 87 (2004).

Chen, H., Yang, W., He, Y., Ding, Y., Zhang, L., Tan, C., Lapkin, A. A. and Bavykin, D. V., Heat transfer and flow behaviour of aqueous suspensions of titanate nanotubes (nanofluids). Powder Technol., 183, 63 (2008).

Choi, S. U. S., Zhang, Z. G., Yu, W., Lockwood, F. E. and Grulke, E. A., Anomalous thermal conductivity enhancement in nanotube suspension. Applied Physics Letters, 79, 2252 (2001).

Chon, C. H., Kihm, K. D., Lee, S. P. and Choi, S. U. S., Empirical correlation finding the role of 
temperature and particle size for nanofluid $\left(\mathrm{Al}_{2} \mathrm{O}_{3}\right)$ thermal conductivity enhancement. Applied Physics Letters, 87, No. 15, 153107 (2005).

Das, S. K., Choi, S. U. S. and Patel, H. E., Heat transfer in nanofluids - a review. Heat Transfer Engineering, 27, 3 (2006).

Daungthongsuk, W. and Wongwises, S., A critical review of convective heat transfer of nanofluids. Renewable and Sustainable Energy Reviews, 11, 797 (2007).

Ding, Y., Alias, H., Wen, D. and Williams, R. A., Heat transfer of aqueous suspensions of carbon nanotubes (CNT nanofluids). Int. J. Heat Mass Transfer, 49, 240 (2006).

Ebrahimnia-Bajestan, E., Niazmand, H., Duangthongsuk, W. and Wongwises, S., Numerical investigation of effective parameters in convective heat transfer of nanofluids flowing under a laminar flow regime. International Journal of Heat and Mass Transfer, 54, 4376 (2011).

Farsad, E., Abbasi, S. P., Zabihi, M. S. and Sabbaghzadeh, J., Numerical simulation of heat transfer in a micro channel heat sinks using nanofluids. Heat and Mass Transfer, 47, 479 (2011).

Fazeli, S. A., Hosseini Hashemi, S. M., Zirakzadeh, H. and Ashjaee, M., Experimental and numerical investigation of heat transfer in a miniature heat sink utilizing silica nanofluid. Superlattices and Microstructures, 51, 247 (2012).

Fluent, Fluent 6.3 User Manual, Fluent Incorporated (2006).

Guo, Z. Y. and Li, Z. X., Size effect on single-phase channel flow and heat transfer at microscale. Int. J. Heat Fluid Flow, 24, 284 (2003).

Haghshenas Fard, M., Esfahany, M. N. and Talaie, M. R., Numerical study of convective heat transfer of nanofluids in a circular tube two-phase model versus single-phase model. International Communications in Heat and Mass Transfer, 37, 91 (2010).

Hamilton, R. L. and Crosser, O. K., Thermal conductivity of heterogeneous twocomponent systems. Ind. Eng. Chem. Fundamentals, 1, 187 (1962).

He, Y., Jin, Y., Chen, H., Ding, Y., Cang, D. and Lu, H., Heat transfer and flow behaviour of aqueous suspensions of $\mathrm{TiO}_{2}$ nanoparticles (nanofluids) flowing upward through a vertical pipe. Int. J. Heat Mass Transfer, 50, 2272 (2007).

He, Y., Men, Y., Zhao, Y., Lu, H. and Ding, Y., Numerical investigation into the convective heat transfer of $\mathrm{TiO}_{2}$ nanofluids flowing through a straight tube under the laminar flow conditions. Applied Thermal Engineering, 29, 1965 (2009).
Kalteh, M., Abbassi, A., Saffar-Avval, M. and Harting, J., Eulerian-Eulerian two-phase numerical simulation of nanofluid laminar forced convection in a microchannel. International Journal of Heat and Fluid Flow, 32, 107 (2011).

Kalteh, M., Abbassi, A., Saffar-Avval, M., Frijns, A., Darhuber, A. and Harting, J., Experimental and numerical investigation of nanofluid forced convection inside a wide microchannel heat sink. Applied Thermal Engineering, 36, 260 (2012).

Kamali, R. and Binesh, a. R., Numerical investigation of heat transfer enhancement using carbon nanotube-based non-Newtonian nanofluids. International Communications in Heat and Mass Transfer, 37, 1153 (2010).

Kamyar, A., Saidur, R. and Hasanuzzaman, M., Application of computational fluid dynamics (CFD) for nanofluids. International Journal of Heat and Mass Transfer, 55, 4104 (2012).

Kang, H. U., Kim, S. H. and Oh, J. M., Estimation of thermal conductivity of nanofluid using experimental effective particle volume. Experimental Heat Transfer, 19, 181 (2006).

Li, Q., Xuan, Y. and Wang, J., Investigation on convective heat transfer and flow features of nanofluids. J. Heat Transfer, 125151 (2003).

Mahmoodi, M. and Hashemi, S. M., Numerical study of natural convection of a nanofluid in c-shaped enclosures. International Journal of Thermal Sciences, 55, 76 (2012).

Maiga, S. E. B., Nguyen, C. T., Galanis, N. and Roy, G., Heat transfer behaviours of nanofluids in a uniformly heated tube. Superlattices Microstructures, 35, 543 (2004).

Maiga, S. E. B., Nguyen, C. T., Galanis, N., Roy, G., Mare, T. and Coqueux, M., Heat transfer enhancement in turbulent tube flow using $\mathrm{Al}_{2} \mathrm{O}_{3}$ nanoparticle suspension. International Journal of Numerical Methods in Heat and Fluid Flow, 16, 275 (2006).

Maiga, S. E. B., Paim, S. J., Nguyen, C. T., Roy, G. and Galanis, N., Heat transfer enhancement by using nanofluids in forced convection flows. International Journal of Heat and Fluid Flow 26, 530 (2005).

Manca, O., Nardini, S. and Ricci, D., A numerical study of nanofluid forced convection in ribbed channels. Applied Thermal Engineering, 37, 280 (2012).

Maxwell, J. C., Electricity and Magnetism. Clarendon Press, Oxford (1873).

Maxwell, J. C., A Treatise on Electricity and Magnetism. Oxford University Press, Cambridge (1881). 
Moraveji, M. K., Darabi, M., Haddad, S. M. H. and Davarnejad, R., Modeling of convective heat transfer of a nanofluid in the developing region of tube flow with computational fluid dynamics. International Communications in Heat and Mass Transfer, 38, 1291 (2011).

Pak, B. C. and Cho, Y. I., Hydrodynamic and heat transfer study of dispersed fluids with submicron metallic oxide particles. Exp. Heat Transfer, 11, 151 (1998).

Putnam, S. A., Cahill, D. G., Braun, P. V., Ge, Z. and Shimmin, R. G., Thermal conductivity of nanoparticle suspensions. Journal of Applied Physics, 99, 084308 (2006).

Rana, P. and Bhargava, R., Numerical study of heat transfer enhancement in mixed convection flow along a vertical plate with heat source/sink utilizing nanofluids. Communications in Nonlinear Science and Numerical Simulation, 16, 4318 (2011).

Rostamani, M., Hosseinizadeh, S. F., Gorji, M. and Khodadadi, J. M., Numerical study of turbulent forced convection flow of nanofluids in a long horizontal duct considering variable properties. International Communications in Heat and Mass Transfer, 37, 1426 (2010).

Roy, G., Nguyen, C. T. and Lajoie, P. R., Numerical investigation of laminar flow and heat transfer in a radial flow cooling system with the use of nanofluids. Superlattices Microstructures, 35, 497 (2004).

Shah, R. K., Thermal entry length solutions for the circular tube and parallel plates. Proceedings of 3rd National Heat and Mass Transfer Conference, Indian Institute of Technology, Bombay, pp. 1175 (1975).

Singh, P. K., Harikrishna, P. V., Sundararajan, T. and Das, S. K., Experimental and numerical investigation into the hydrodynamics of nanofluids in microchannels. Experimental Thermal and Fluid Science, 42, 174 (2012).

Tahery, A. A., Zehforoosh, A. and Pesteei, S. M., Numerical investigation on the use of nanofluids in natural convection heat exchangers using a mixture-phase approach. Heat Transfer-Asian Research, 40, 756 (2011).

Wang, X. Q. and Mujumdar, A. S., Heat transfer characteristics of nanofluids: A review. International Journal of Thermal Sciences, 46, 1 (2007).

Wen, D. and Ding, Y., Experimental investigation into convective heat transfer of nanofluids at the entrance region under laminar flow conditions. Int. J. Heat Mass Transfer, 475181 (2004).

Williams, W. C., Buongiorno, J. and Hu, L.W., Experimental investigation of turbulent convective heat transfer and pressure loss of alumina/water and zirconia/water nanoparticle colloids (nanofluids) in horizontal tubes. J. Heat Transfer, 130, 040301.1 (2008).

Xuan, Y. and Li, Q., Heat transfer enhancement of nanofluids. International Journal of Heat and Fluid Flow, 21, 58 (2000).

Xuan, Y., Li, Q. and Hu, W., Aggregation structure and thermal conducting of nanofluids. AIChE Journal, 49, 1038 (2004).

Xue, Q. Z., Model for effective thermal conductivity of nanofluids. Physics Letters, A 307, 313 (2003).

Yamada, E. and Ota, T., Effective thermal conductivity of dispersed materials. Wrme-und Stoffübetragung, 13, 27 (1980).

Yang, Y.-T. and Lai, F.-H., Numerical investigation of cooling performance with the use of $\mathrm{Al}_{2} \mathrm{O}_{3}$ / water nanofluids in a radial flow system. International Journal of Thermal Sciences, 50, 61 (2011).

Yang, Y., Zhang, Z. G., Grulke, E. A., Anderson, W. B. and $\mathrm{Wu}$, G., Heat transfer properties of nanoparticle-in-fluid dispersions (nanofluids) in laminar flow. Int. J. Heat Mass Transfer, 48, 1107 (2005).

Yoo, D. H., Hong, K. S. and Yang, H. S., Study of thermal conductivity of nanofluids for the application of heat transfer fluids. Thermochimica Acta, 455, 66 (2007).

Yu, Z.-T., Xu, X., Hu, Y.-C., Fan, L.-W. and Cen, K.-F., Numerical study of transient buoyancydriven convective heat transfer of water-based nanofluids in a bottom-heated isosceles triangular enclosure. International Journal of Heat and Mass Transfer, 54, 526 (2011).

Zhang, X., Gu, H. and Fujii, M., Effective thermal conductivity and thermal diffusivity of nanofluids containing spherical and cylindrical nanoparticles. Experimental Thermal Fluid Science, 31, 593 (2007). 